\title{
Vietnam Primary School Students' Ability of Applying Mathematics Knowledge into Real Life
}

\author{
Dr Le Thi Thu Huong \\ Thai Nguyen University of Education \\ Prof. Nguyen Huu Chau \\ Hanoi National University
}

\begin{abstract}
Mathematics is closely related to reality and widely applied in many different fields of science, technology as well as in real life. With its special role, Mathematics is essential for all sciences, contributing to an increasingly modern and civilized social life. This paper presents a study of the arrangement of practical elements in Mathematics textbooks and the analysis of primary school students' abilities in applying Mathematics knowledge into practice. This research also aims to emphasize the importance of developing students' mathematical application competencies in teaching and learning mathematic in primary schools and the need to change teachers' perceptions and actions through some recommendations accordingly.
\end{abstract}

Keywords: school mathematics ;apply math into real life ; primary school students

\section{INTRODUCTION}

Developing the knowledge application competency for students is an important goal in math education and should begin in the early years of primary school.

According to Berinderjeet KAUR, "Application and Modelling play a vital role in the development of mathematical understanding and competencies. It is important that students apply mathematical problem-solving skills and reasoning skills to tackle a variety of problems, including real-world problems" [0].

The knowledge application competency is the ability of the learner to mobilize, use the knowledge, skills learned in the classroom or learn from real life experiences to solve the problems in diverse and complex situations in an effective and capable ways. The knowledge application competency is reflected in the quality and personality of people in the course of their activities to satisfy the demand of knowledge acquisition.

Applying mathematical knowledge to practice includes the use of existing knowledge to solve cognitive problems and the application of knowledge to practical production in daily life such as practice exercise, experiment, modelling, applying to other subjects that have many direct applications in life such as chemistry, physics, biology, etc or simply daily calculation. In particular, the application competency is the combination of unique attributes of the distinct qualities of human beings to adapt to real life.

The mathematical knowledge application competency in the fact is the ability to apply mathematical knowledge acquired in a given subject for practical application, such as the application of spatial geometry knowledge to calculate the volume of objects in your daily life 
using the trigonometric knowledge to measure the height of a real object in real life in which there is a point that you can not reach, measure the distance between two points.

The mathematical knowledge application competency in the fact is the ability to apply mathematical knowledge acquired in a given subject for practical application, such as the application of spatial geometry knowledge to calculate the volume of objects in your daily life using the trigonometric knowledge to measure the height of a real object in real life in which there is a point that you can not reach, measure the distance between two points.

The knowledge application competency is to promote the linkage of theoretical and practical knowledge in the school in real life, to accelerate the "practice makes perfect" teaching practice.

According to the analysis above, it is understood that the knowledge application competency can be defined that is the ability to apply proficiently and regularly the acquired mathematical knowledge to solve the problems in practical life.

This competency can be described in details as follows:

- Ability to apply mathematical knowledge as learning tools.

- Ability to solve some typical problems.

- Ability to apply mathematical knowledge, mathematical thinking methods into practice.

- Ability to detect, analyze and transfer real situations into mathematical problems learned.

- Ability to transfer from mathematical knowledge learned into common situations in reality.

From the interpretation above, the knowledge application competency can be described into different levels of knowledge application competency, namely:

- According to the mathematical knowledge background, it should be used to determine different levels such as students only need to apply a unit of mathematical knowledge or apply a combination of mathematical knowledge to solve a problem.

- According to the level of familiarity or creativity of students.

- According to the level of student involvement in problem-solving.

- According to the level of cognition of the students: to reproduce the mathematical knowledge to answer the theoretical question; apply mathematical knowledge to explain events and phenomena of theory; apply mathematical knowledge to solve situations in practice; apply mathematical knowledge and skills to solve real-world situations, the ability to link mathematical knowledge learned with real-world situations or scientific research, planning for specific actions to be taken or writing report.

\section{PRACTICAL ELEMENTS INCLUDED IN MATHEMATICS TEXTBOOKS IN PRIMARY SCHOOLS IN VIETNAM}

The content of mathematical knowledge is practically applied in mathematics textbooks of primary classes

Through researching the mathematics curriculum and textbooks in the first grades of primary school, it is clear that the potential mathematical knowledge application in practice is presented as follows: 
Table 1. The content of practical knowledge in Mathematics grade 1, 2, 3 in Vietnam Mathematics curriculum

\begin{tabular}{|c|c|c|}
\hline Grade & Content & Knowledge can be applied in reality \\
\hline \multirow{3}{*}{1} & Numbers & $\begin{array}{l}\text { Natural numbers up to } 100 \\
\text { Addition, subtraction for natural numbers up to } \\
100 \\
\text { Compare natural numbers }\end{array}$ \\
\hline & Measurement & $\begin{array}{l}\text { Centiment } \\
\text { Days in a week } \\
\text { Clock. Time }\end{array}$ \\
\hline & Geometric elements & $\begin{array}{l}\text { Square, circle } \\
\text { Triangular } \\
\text { Point. Line segment } \\
\text { Measuring length }\end{array}$ \\
\hline \multirow{3}{*}{2} & Numbers & $\begin{array}{l}\text { Natural numbers up to } 1000 \\
\text { Addition, subtraction, multiplication, division for } \\
\text { natural numbers } \\
\text { Compare natural numbers }\end{array}$ \\
\hline & Measurement & $\begin{array}{l}\text { Kilogram } \\
\text { Date, Time } \\
\text { Date, month } \\
\text { Read clocks and tell time } \\
\text { Read calendar } \\
\text { Hour, minute } \\
\text { Meter } \\
\text { Kilometer } \\
\text { Millimeter } \\
\text { Vietnam currency }\end{array}$ \\
\hline & Geometric elements & $\begin{array}{l}\text { Rectangle. Quadrangle } \\
\text { Straight line } \\
\text { Broken line, length of a broken line } \\
\text { Perimeter of triangles. Perimeter of quadrangles }\end{array}$ \\
\hline \multirow{3}{*}{3} & Numbers & $\begin{array}{l}\text { Numbers up to } 1000 \\
\text { Addition, subtraction, multiplication, division for } \\
\text { natural numbers up to } 1000 \\
\text { Compare numbers }\end{array}$ \\
\hline & Measurement & $\begin{array}{l}\text { Decameter, Hectometer } \\
\text { Gram } \\
\text { Vietnam currency } \\
\text { Square centimeter }\end{array}$ \\
\hline & Geometric elements & $\begin{array}{l}\text { Square angle, non square angle } \\
\text { Measuring length } \\
\text { Midpoint. Midpoint of a line segment } \\
\text { Circle, center, radius, diameter } \\
\text { Area of a rectangular } \\
\text { Area of a square }\end{array}$ \\
\hline
\end{tabular}


The number of the practical problems in the textbook Mathematics garde1, Mathematics grade2, Mathematics grade 3.

We conducted a survey of mathematics textbook Grade 1, Grade 2, Grade 3 on the number of exercises/ problems in the practical situation and obtained the results as follows:

Table 2. Number of problems with practical content in mathematics textbooks Grade 1, 2, 3 in Vietnam curriculum

\begin{tabular}{|c|c|c|c|}
\hline Grade & $\begin{array}{c}\text { Total of Math } \\
\text { Problems }\end{array}$ & $\begin{array}{c}\text { Number of problems with practical } \\
\text { content }\end{array}$ & Percentage \\
\hline 1 & 510 & 75 & $14,7 \%$ \\
\hline 2 & 675 & 101 & $14,9 \%$ \\
\hline 3 & 663 & 103 & $15,5 \%$ \\
\hline
\end{tabular}

Based on the results of the survey, it was found that the percentage of practical problems in the first grades was similar and the number was not much. The practical situations in the textbook are largely hypothetical, somewhat outdated (because it was written in 2000). As a result, reallife problems in the textbooks were largely no longer relevant to the realities of life today.

In addition, in order to find out the teacher's comments on the practical problems of textbooks in Grade 1, Grade 2 and Grade 3 textbooks, we interviewed some teachers on duty. In mathematics in primary school, $90.5 \%$ of teachers have affirmed that many contents of mathematics introduced to students in grades 1, 2 and 3 are related to real life; However, the system of problems linked to the practical situation in the textbooks was $83.3 \%$ of teachers stated that the level is normal, even less practical to the real life. In particular, since textbooks were written in the early 2000's, mathematical situations associated with real life were no longer relevant to today's life. However, in order to replace the old situation, teachers are still confused how to design the problems to suit the current practice, and also ensure the knowledge and skills of the subject.

Most teachers find that there are not many problems to improve the skills of applying mathematics into practice in textbooks, many problems are no longer suitable but teachers are confused to adjust or change because it needs to ensure that the standards of knowledge and skills of the subjects. When assessing the level of mathematical application in the practice, $85.7 \%$ of teachers rated normal level, the remaining $14.3 \%$ rated good. This result partly reflects the fact that teachers have not really focused on refining their mathematical skills to solve real life situations. This requires teachers to adjust and add updated practical situations appropriate to the local and ensure the knowledge and skills of the subject.

\section{A SURVEY ON VIETNAMESE STUDENTS' COMPETENCY OF APPLYING MATHEMATICS KNOWLEDGE INTO PRACTICE}

We conducted a survey on mathematics application competency of primary school students in three provinces of Vietnam (Thai Nguyen, Lang Son, Bac Giang). The sample consisted of 15 teachers and 218 students in grades 1, 2 and 3 in some primary schools in the three provinces.

The content of the survey focuses on:

- Teachers' perceptions of the urgency of developing the mathematics application competency at very first grades of primary school

- The situation in applying mathematics in practice for students in the first grades of primary school. 
- Assess the level of mathematical application in the practice of students in the first grades of primary school.

During the survey we have implemented the following methods:

- Questionnaire surveys and interviews with primary school teachers

- Observe the activities of teachers and students in classroom.

- Organize students to do math exercises that contain practical problems and assessments of student's work.

From the research we obtained the following data and information:

Table 3. Teachers' Evaluation of Level of necessity

to develop the mathematics application competency of early primary school students

\begin{tabular}{|c|c|c|c|}
\hline & $\begin{array}{c}\text { Very } \\
\text { Necessary }\end{array}$ & Necessary & Not Necessary \\
\hline $\begin{array}{c}\text { Teachers' Evaluation } \\
\text { of Level of necessity }\end{array}$ & 89.9 & 10.1 & 0 \\
\hline
\end{tabular}

The above table shows that $100 \%$ of teachers are aware of the need to develop mathematical application competency in early primary school students. Early primary school mathematics is simple but it sets the foundation knowledge and potentially relevant to the real-life situation of students if the teacher is skillful and flexible in applying the knowledge.

Table 4. Frequency of competency training on maths application in practice

\begin{tabular}{|l|c|c|c|c|}
\hline \multicolumn{1}{|c|}{ Areas of assessment } & \multicolumn{3}{c|}{ Frequency (\%) } \\
\cline { 2 - 5 } & Never & Rarely & $\begin{array}{c}\text { Sometime } \\
\text { S }\end{array}$ & Regularly \\
\hline $\begin{array}{l}\text { Motivate learning for students through } \\
\text { problematic situations linked to practice }\end{array}$ & 0 & 23.8 & 69 & 7.2 \\
\hline $\begin{array}{l}\text { Explore life experience using media and visal } \\
\text { teaching materials }\end{array}$ & 0 & 16.7 & 71.4 & 11.9 \\
\hline $\begin{array}{l}\text { Understand the application of math to practical } \\
\text { life }\end{array}$ & 0 & 31 & 69 & 0 \\
\hline $\begin{array}{l}\text { Develop situations, questions, exercises with } \\
\text { practical content in teaching mathematics in } \\
\text { the first grades of primary school }\end{array}$ & 0 & 19 & 76.2 & 4.8 \\
\hline $\begin{array}{l}\text { Organize extra-curricular activities associated } \\
\text { with real life mathematics }\end{array}$ & 14.3 & 61.2 & 24.5 & 0 \\
\hline
\end{tabular}

From the above results, we found that, despite being aware of mathematical application competency into practice, the teachers seem to be hesitant in applying maths in reality. That leads to the fact that the motivation of students to learn through practical situations is only $7.2 \%$ doing at regular basis; $11.9 \%$ regularly explore life experience and $71.4 \%$ teachers are sometimes interested in fostering mathematical competencies in practice for students in mathematics teaching; There are only 4.8\% teachers organizing learning games associated with solving practical situations. The remaining teachers occasionally or rarely apply. The 
extra-curricular activities associated with the realities of life are even less, only $24.5 \%$ of teachers to do occasionally, the rest is rarely organized and never organized this activity.

To explain the causes of this situation, we study the difficulties that teachers encounter in the process of improving mathematical competencies in practice for students in the first grades of primary school and get the following results.

Table 5. Difficulties when implementing mathematics application in practice

\begin{tabular}{|l|l|l|}
\hline No & \multicolumn{1}{|c|}{ Difficulties } & \multicolumn{1}{|c|}{$\%$} \\
\hline 1 & $\begin{array}{l}\text { Not equipped with pedagogical skills to practice mathematical skills in } \\
\text { practice for students }\end{array}$ & 93.1 \\
\hline 2 & The habit of designing a traditional lesson plan depends on the textbook & 69.7 \\
\hline 3 & Textbook content does not have many practical content & 65.1 \\
\hline
\end{tabular}

The above analysis shows that the greatest difficulty in implementing mathematical application competency in practice is that teachers are not equipped with the necessary pedagogical skills and are well-trained. From there, the habit of designing teaching activities focuses on theory without paying attention to the life experience of students.

In addition to the questionnaire survey, we conducted the classroom observation in the classroom, although the knowledge of mathematics was provided to the students during the lesson, teachers are hesitant in referring the knowledge to reality. In the professional development, the mathematical application into practice has not been mentioned much. Teachers have not paid much attention to understanding the practical origins of mathematics and the mathematical problems that come back to practice. Through direct discussion, many teachers admitted that although they wanted to create situations for students to use mathematics in practice but they do not know how to do.

To evaluate the components of mathematical application competency in the practice of primary school students, we designed a survey based on Likert's 4-level scale with the coding of the degree of achievement corresponding to the lowest level $(=1)$ to the highest $(=4)$. The table below summaries the average score on the level of competency elements used in the practice of 218 elementary school students in the survey. 
Table 6. Level of achievement of components of mathematics application competencies

Components of mathematics application competencies

Competency to apply the knowledge of math (mostly standard knowledge) as a tool in learning.

Compentency to solve some typical problems

\begin{tabular}{|l|c|}
\hline \multicolumn{1}{|c|}{ Description } & $\begin{array}{c}\text { Avarage } \\
\text { Score }\end{array}$ \\
\hline $\begin{array}{l}\text { 1. State math definitions, formulas, } \\
\text { properties }\end{array}$ & 2.9 \\
\hline 2. Apply proficiently mathematical rules & 2.7 \\
\hline 1. Learning problems competency & 2.5 \\
\hline 2. Planning problem solving competency & 2.6 \\
\hline 3. Problems presentation competency & 2.5 \\
\hline $\begin{array}{l}\text { 4. Looking back the problems competency } \\
\text { 1. Find the "keyword" in the problem, } \\
\text { remove the non-essential elements }\end{array}$ & 2.5 \\
\hline $\begin{array}{l}\text { 2. Convert natural language into } \\
\text { mathematical language }\end{array}$ & 2.4 \\
\hline $\begin{array}{l}\text { 3. Address the problem from a practical } \\
\text { situation }\end{array}$ & 2.4 \\
\hline $\begin{array}{l}\text { 4. Solve practical problems with learned } \\
\text { mathematics }\end{array}$ & 2.1 \\
\hline $\begin{array}{l}\text { 1. Get practical examples to illustrate } \\
\text { mathematical concepts }\end{array}$ & 2.5 \\
\hline $\begin{array}{l}\text { 2. Detect real-life situations associated } \\
\text { with learning math }\end{array}$ & 1.8 \\
\hline
\end{tabular}

Competency transferred from

mathematical knowledge learned into common situations in practice.
Competency to detect, analyze and translate real-world situations into mathematical problems learned.

The above results suggest that the competency to apply mathematics to the practice of primary school students is still limited, especially the competency to detect practical situations associated with mathematical content being learned (1.8). Although the average score for Competence in Applied Mathematics (mostly standard knowledge) as a learning tool and the competency to solve a number of practical problems is relatively high (over 2.5) but the competency to switch between real-life problems and their math content is low (under 2.5). Therefore, in the process of teaching, the fostering and development of mathematics application competency to students are very necessary. We suggest some ways to do as following:

\section{Design realistic problem-solving situations for teaching mathematics}

The problematic situation in teaching mathematics is the situation in which the student needs to solve a given task, but his or her knowledge, skills, experience has not helped students solve the situation immediately because there are no obvious solutions. Margaret confimed that "teaching Mathematics at primary school through problem-solving contexts and inquiryoriented environments which are characterized by the teacher helping students construct a deep understanding of mathematical ideas and processes by engaging them in doing mathematics: creating, conjecturing, exploring, testing, and verifying" [0]. When describing the description of a realistic problem, Schoenfeld also said that that is not only "a vehicle for students to construct, evaluate and refine their own theories about mathematics and the theories of others" but also "create a context" and "consider the possibility of applying such mathematical knowledge in the everyday practical life of the student" [0]. These situations can be implemented in various forms of practice such as testing conjectures, posing problems, looking for patterns, and exploring alternative solution paths. Moreover, because application and modeling tasks are typically posed in group work settings they also involve a range of metacognitive and communication practices 
$[0$, p.22].

\section{Build a system of math problems with content attached to reality}

"Real life Maths is intended to maximize readability and accessibility by minimizing the use of equations, example problems, proofs, etc. Accordingly, real-life Maths is not a math textbook, nor is it designed to fully explain the mathematics involved in each concept. Rather, Real life Maths is intended to complement the mathematics curriculum by serving a general reader for maths by remaining focused on fundamental math concepts as opposed to the history of math, biographies of mathematicians, or simply interesting applications" [0, p.xx]. Teachers should also substitute homework assignments with projects or practical problems. There are many ways for teachers to develop practical exercises, such as:

- Creating the problems from the problems in the textbook by attaching more practical factors;

- Creating the problems from a given summary by attaching it to the practical factor;

- Creating the realistic mathematical problems based on the name of the mathematical form;

- Making a completely new practical problems

\section{Organizing experience activities with content related to applying mathematics in practice}

The experience activities in the new curriculum has made the content of education not narrow in textbooks, but closely related to the reality of social life; It is the path that connects theories to the realities, creating the unity of perception and action, contributing to the development of qualities, thoughts, wills, emotions, values, life skills, good faith in students, forming the necessary human capacities in modern society. It is also the way to develop the whole personality of students, meeting the goal of general education reform in Vietnam [0]. Therefore, this is one of the effective methods for teachers to incorporate teaching content in the school closer to their living capital.

\section{Increasing the number of math problems related to practice in the formal test or evaluation of student learning outcomes}

From the point of view of competency-based education development, the evaluation of student learning outcomes should not take into account the ability to reproduce learned knowledge at the heart of the assessment. It should focus on knowledge application in different real-life situations through specific exercises.

To demonstrate that students have the competencies at certain extent, it is necessary to provide opportunities for students to solve problems in practical situations. At the same time, students have to apply the knowledge and skills they have learned in school, while using their own experience gained from the experiences outside the school (family, community). Thus, through the completion of a task in the real context, one can simultaneously examine and evaluate both the cognitive skills, performance skills and the values and emotions of the learners.

\section{CONCLUSION}

Mathematics provides a way of viewing and making sense ofthe world It isused to analyse and communicate information and ideas and to tackle a range of practical tasks and real life also the material and means for creating new imaginative worlds to explore. Through explortion within mathematics itsel new mathematics is created and current ideas are modified and extended" [0, p.11]. Organizing for students to acquire knowledge, skills through exercises, situations associated with real life is one of the steps to make students more active, selfmotivated in acquiring knowledge, contributing to the positive, active and creative students in 
the process of learning which is following the the orientation of "strongly transforming the educational process from mainly equipping knowledge to comprehensive development of student's competencies and qualities. Educational activities must be conducted on the principles of learning coupled with practice, education combined with production, theories closely linked to reality, and education at school combined with education in the family and in the society.

\section{References}

Ministry of Education and Training (2017), Vietnam General Education Curriculum.

Berinderjeet Kaur, Jaguthsing Dindyal (2000), Mathematical Applications and Modeling, World Scientific Publishing, British.

Evan M. Glazer, John W. McConnell (2002), Real-life math: Everyday use of mathematical concept, Greenwood Press.

Jan Winter, Jane Andrews, Pamela Greenhough, Martin Hughes, Leida Salway and Wan Ching Yee (2009), Improving Primary Mathematics Linking home and school, Routledge Publisher.

K. Lee Lerner \& Brenda Wilmoth Lerner (2010), Real-Life Maths, Volume 1: A-L, Thomson Gale Publisher. Margaret T. (2016), Mathematics Through Problem Solving, Institue of Sathya Education, Hong Kong.

Schoenfeld, A. H (1994), Mathematical Thinking and Problem Solving, Hillsdale, NJ: Lawrence Erilbaum Associates. Valsa Koshy, Paul Ernest and Ron Casey(2000), Mathematics for Primary Teachers, Routledge Publisher. 